\title{
Nitric Oxide and Peptide Neurohormones Activate cGMP Synthesis in the Crab Stomatogastric Nervous System
}

\author{
Nathaniel L. Scholz, ${ }^{1}$ Michael F. Goy, ${ }^{2}$ James W. Truman, ${ }^{1}$ and Katherine Graubard ${ }^{1}$ \\ 1Zoology Department, University of Washington, Seattle, Washington 98195-1800, and ${ }^{2}$ Department of Physiology, \\ University of North Carolina, Chapel Hill, North Carolina 27599-7545
}

In the neural circuits that comprise the crustacean stomatogastric nervous system (STNS), synaptically delivered neurotransmitters and circulating neurohormones elicit a wide range of rhythmic motor ouputs. However, functional roles for second messengers in this system are poorly understood. Here we demonstrate two different signaling pathways that control the synthesis of $3^{\prime}, 5^{\prime}$-cGMP in the crab STNS. One pathway is activated by nitric oxide (NO) and is mediated by a cytoplasmic guanylate cyclase. A second pathway is stimulated by peptidecontaining extracts from a crab neurohemal organ that activate a membrane-associated guanylate cyclase. Using wholemount immunocytochemistry to localize individual cGMPcontaining cells, we find that NO elevates intracellular cGMP in a small subset of STNS neurons. Immunopositive cells are found predominantly in the stomatogastric ganglion, with a few additional cells located in the oesophageal and commissural ganglia. Crab tissues differ in their sensitivities to NO and to the peptide-containing extract. The NO-mediated pathway is apparently restricted to the nervous system, whereas the peptidemediated pathway is present in every tissue tested. The results of these experiments demonstrate that multiple signaling pathways involving cGMP are present in the STNS and suggest that this second messenger may help control the metabolic and physiological status of these motor circuits.

Key words: crustacean; cGMP; nitric oxide; guanylate cyclase; peptide; crustacean hyperglycemic hormone; immunocytochemistry
Many neurotransmitters and hormones modulate target cells by elevating intracellular concentrations of 3',5'-cGMP (Goy, 1991; Waldman and Murad, 1987). Synthesis of cGMP is under the control of two broad classes of guanylate cyclase (Yuen and Garbers, 1992; Schmidt et al., 1993): a family of soluble enzymes, which can be stimulated by the inter- and intracellular messenger nitric oxide (NO), and a family of membrane-associated enzymes, which can be stimulated by peptide agonists. In the vertebrate CNS, cGMP plays an important role in diverse processes, including visual transduction (Stryer, 1986), olfaction (Breer and Shepherd, 1993), and synaptic transmission (Arancio et al., 1995).

In vertebrates, NO-activated cGMP has also been implicated in the regulation of the enteric nervous system, including control of peristaltic contractions and reflex responses throughout the gastrointestinal tract (Rand and $\mathrm{Li}, 1995$ ), modulation of synaptic efficacy (Baccari, 1994; Yuan et al., 1995), and shifting of patterned motor output from an active to a postprandial quiescent state (Rodríguez-Membrilla et al., 1995). Furthermore, a family of peptides (e.g., guanylin and uroguanylin) regulates intestinal ion transport by activating a membrane-associated guanylate cyclase (Wiegand et al. 1992; Ham et al., 1993).

cGMP may also serve functional roles in olfaction, feeding, and digestion among invertebrates. For example, NO-mediated signaling pathways occur in the olfactory centers of insects (Müller and Bicker, 1994; Elphick et al., 1995) and terrestrial molluscs (Gelperin, 1994).

Received Oct. 5, 1995; revised Nov. 30, 1995; accepted Dec. 1, 1995.

This work was supported by a predoctoral National Research Service Award Traineeship to N.L.S., National Science Foundation Grant IBN9242993 to J.W.T., and National Institutes of Health Grants NS25915 (M.F.G.) and NS15697 (K.G.). We thank Jan De Vente for his generous gift of the anti-cGMP antibody and Subhash Prabhakar for his valuable assistance with RIAs.

Correspondence should be addressed to Nat Scholz, Department of Zoology, P.O. Box 351800, University of Washington, Seattle, WA 98195-1800.

Copyright (C) 1996 Society for Neuroscience $0270-6474 / 96 / 161614-09 \$ 05.00 / 0$
The buccal ganglia of snails contain neurons that are immunopositive for NO synthase (NOS) and motor patterns associated with feeding are elicited with exposure to NO (Moroz et al., 1993). Finally, the crustacean hyperglycemic peptides (CHHs), which act through a membrane guanylate cyclase (Goy, 1990), control glucose metabolism and energy storage in the hepatopancreas (Sedlmeier and Keller, 1981) and the secretion of digestive enzymes (Sedlmeier, 1988).

The stomatogastric nervous system (STNS) of decapod crustaceans is an important model for studying how patterned motor output is generated by ensembles of neurons. Furthermore, it is the main neuronal network controlling digestive function. Within the stomatogastric ganglion (STG), $\sim 30$ neurons are loosely organized into two central pattern-generating (CPG) circuits that coordinate the movements of the gastric mill and pylorus. The physiological properties of STG neurons have been studied intensively, as has their modulation by an array of synaptically delivered peptidergic and aminergic neurotransmitters (Harris-Warrick et al., 1992). Despite this, little is known about transmitter-activated second messenger pathways in this system.

As a first step toward understanding how cGMP participates in the physiological organization of STNS networks, we used anti-cGMP radioimmunoassays (RIAs) and anti-cGMP immunocytochemistry (ICC) to investigate the effects of NO and crustacean neuropeptides on cGMP biosynthesis in the STNS. This approach permits a quantitative analysis of overall increases in cGMP content in the STNS, and provides an anatomical map of specific populations of responsive cells.

\section{MATERIALS AND METHODS}

Animals and materials

Adult male rock crabs (Cancer productus) were hand-collected from Puget Sound and maintained without food in seawater aquaria at $12^{\circ} \mathrm{C}$. Animals were anesthetized by chilling on ice, and then the STNS (Fig. 1) 


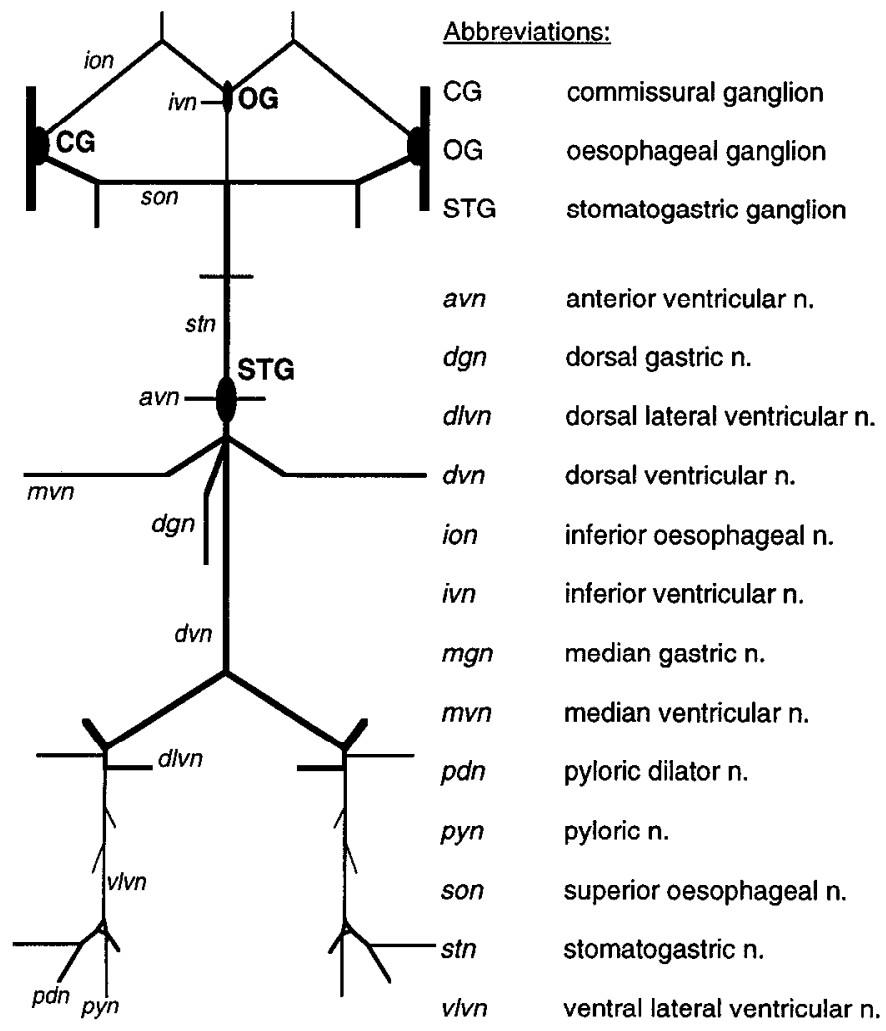

Figure 1. Schematic diagram of the crab STNS. The indicated abbreviations are used throughout the text.

was dissected as described by Mulloney and Selverston (1974). Briefly, the foregut was removed, cut ventrally, and pinned with the dorsal side up in a dish containing cold crab saline $(440 \mathrm{~mm} \mathrm{NaCl}, 11 \mathrm{~mm} \mathrm{KCl}, 13 \mathrm{~mm}$ $\mathrm{CaCl}_{2}, 26 \mathrm{mM} \mathrm{MgCl}$, and $10 \mathrm{~mm}$ HEPES, pH-adjusted to 7.4 with $\mathrm{NaOH}$ ). The STNS, consisting of the STG, the oesophageal ganglion (OG), the paircd commissural ganglia (CGs), and anterior nerves (son, $i o n$, and $s t n$ ), was isolated from the foregut and transferred to a $2 \mathrm{ml} /$ well tissue culture dish (Nunclon). In a few experiments, the posterior nerves were also included. All other tissues were dissected in cold saline and transferred to glass vials.

\section{ICC}

Stimulation with NO donors. Nervous systems were stimulated for $15 \mathrm{~min}$ in vitro by replacing the bathing solution with crab saline containing the phosphodiesterase inhibitor isobutylmethylxanthine [0.5 mM 1-methyl-3isobutylxanthine (IBMX), Sigma, St. Louis, MO] and $10 \mathrm{~mm}$ sodium nitroprusside (SNP, Sigma), 1 mm 3-morpholino-sydnonimine (SIN-1, Biomol, Plymouth Meeting, PA), or $1 \mathrm{mM} S$-nitroso- $N$-acetylpenicillamine (SNAP, Biomol). SNAP was first dissolved in a small volume of dimethylsulfoxide (DMSO; $1 \%$ final concentration). Each NO donor is maximally active in rat cerebellar slices at these concentrations (Southam and Garthwaite, 1991). Additional nervous systems were treated with NO donors alone, IBMX alone, or were left untreated.

Stimulation with peptide extract. Individual sinus glands were isolated from eyestalks and homogenized in saline containing $0.5 \mathrm{~mm}$ IBMX. Twelve sinus glands were homogenized per $\mathrm{ml}$ saline. From this stock solution, peptide extract was applied in IBMX-containing saline to in vitro nervous systems for $90 \mathrm{~min}$ (the longest time interval at which the response is still linear) at a final concentration of $10 \mu \mathrm{l} / \mathrm{ml}$.

cGMP immunostaining. The rabbit anti-cGMP polyclonal antibody used in this study has been described previously (De Vente et al., 1987). Free-floating nervous systems were fixed overnight at $4^{\circ} \mathrm{C}$ in $4 \%$ paraformaldehyde (Electron Microscopy Sciences, Ft. Washington, PA) in $0.1 \mathrm{M}$ PBS. Tissues were washed in PBS containing $0.3 \%$ Triton X-100 (PBST; Sigma) and incubated overnight with a rabbit anti-cGMP antiserum (1:1000, donated by Dr. Jan De Vente, University of Limburg, The Netherlands). After a second wash series in PBST, STNSs were incubated overnight in a biotinylated goat anti-rabbit secondary antibody (1:1000;
Vector Laboratories, Burlingame, CA), and cGMP-like immunoreactivity was visualized with an avidin-biotin-peroxidase complex (ABC Kit, Vector) using $0.5 \mathrm{mg} / \mathrm{ml}$ diaminobenzidine (DAB) and $0.003-0.01 \% \mathrm{H}_{2} \mathrm{O}_{2}$ (Sigma). In some experiments, a peroxidase-conjugated goat anti-rabbit secondary antibody (1:300, Jackson Immunoresearch, West Grove, PA) was used, and the sites of antibody binding were visualized with DAB using the glucose oxidase technique (Watson and Burrows, 1981). The latter approach generally resulted in a lower background. Labeled nervous systems were arranged on poly-L-lysine-coated coverslips, dehydrated in alcohol, cleared in xylene, and mounted in DPX Mountant (Fluka, Buchs, Switzerland) or Permount (Fisher, Pittsburgh, PA).

Controls. The specificity of the anti-cGMP antibody for its antigen has been characterized in detail (De Vente et al., 1987). In this study, we preabsorbed the primary antiserum at room temperature for $1 \mathrm{hr}$ in known concentrations of cGMP, cAMP, or GMP (Sigma), and subsequently applied the preabsorbed antiserum to STNSs that had been stimulated with NO and IBMX. Tissues were also processed in the absence of primary antisera.

\section{RLAs}

A competitive binding assay (RIA) was used to measure the cGMP content of STNSs in each treatment group (Goy, 1990). Treatment groups and stimulus concentrations were identical to those for immunocytochemical experiments. Nervous systems were preincubated $\left(12^{\circ} \mathrm{C}\right)$ for $30 \mathrm{~min}$ in saline (containing IBMX where required), stimulated for 15 min (NO donors) or 90 min (peptide extract), and homogenized in 6\% trichloroacetic acid (TCA). Each homogenate was centrifuged, and the cGMP content (soluble fraction) was determined by RIA after ether extraction to eliminate TCA (Brooker et al., 1979). The antibody was obtained from Woods Assay (Portland, OR), and the $\left[{ }^{125} \mathrm{I}\right] 2^{\prime}-o$ monosuccinylguanosine $3^{\prime}, 5^{\prime}$ cyclic monophosphate tyrosylmethylester trace was preparcd according to standard procedures (Hunter and Greenwood, 1962). Values were corrected for protein content using a spectrophotometric dye-binding assay (Bio-Rad, Hercules, CA) based on the method by Bradford (1976).

\section{Guanylate cyclase assay}

We assayed cytosolic and membrane fractions of the STNS for guanylate cyclase activity following the procedure outlined by Goy (1990). In each experiment, STNSs (4 total) were dissected in cold saline and homogenized in $1.5 \mathrm{ml}$ of buffer B (50 mM HEPES, $1 \mathrm{~mm}$ EDTA, and $0.1 \%$ bacitracin, $\mathrm{pH} 7.4$ ). The homogenate was centrifuged for $1 \mathrm{hr}$ at 100,000 $\times g\left(4^{\circ} \mathrm{C}\right)$, and the upper two-thirds of the soluble fraction was retained. The remaining supernatant was discarded, and the membranes were washed by vortexing in buffer $\mathrm{C}$ (buffer $\mathrm{B}$ plus $100 \mathrm{~mm} \mathrm{KCl}$ ) and centrifuging for $1 \mathrm{hr}$ at $100,000 \times g$. This step was repeated using buffer $\mathrm{B}$ instead of buffer $\mathrm{C}$, and the final pellet was resuspended by homogenization in buffer $\mathbf{B}$. Aliquots of both fractions were assayed for protein content (as above).

Cyclase activity was assayed at 4,10 , and $20^{\circ} \mathrm{C}$. Aliquots of each fraction were mixed with buffer A [ $50 \mathrm{mM}$ HEPES, $8 \mathrm{mM} \mathrm{MgCl}, 2 \mathrm{mM}$ IBMX, $4 \mathrm{mM}$ GTP, $60 \mathrm{~mm}$ phosphocreatine, $800 \mu \mathrm{g} / \mathrm{ml}$ creatine kinase (185 U/mg), and $1 \mathrm{mg} / \mathrm{ml} \mathrm{BSA}, \mathrm{pH} 7.4$ ], to which we had added $10 \mathrm{~mm}$ SNP, $10 \mu \mathrm{l} / \mathrm{ml}$ peptide extract, or an equivalent volume of buffer B. Cyclase activity was terminated at various times $(15,30$, and $45 \mathrm{~min}$ ) with $6 \%$ TCA, and cGMP was measured by RIA after ether extraction. The rate of synthesis was determined as the slope of a straight line fit by linear regression to each time course.

\section{RESULTS}

\section{NO donors activate cGMP synthesis in the STNS}

In the vertebrate nervous system, NOS enzymes generate NO from L-Arg. As a nonpolar gas, NO may then diffuse readily across cell membranes. Several compounds have been used to generate NO in the vicinity of potential neuronal targets (Southam and Garthwaite, 1991). Among these are SNP, SIN-1, and SNAP. We used all three of these donors (each with a different mechanism of $\mathrm{NO}$ release) to ensure that $\mathrm{NO}$, and not an alternate breakdown product, was the stimulus responsible for elevating cGMP. To ascertain whether NO can stimulate cGMP metabolism in the STNS, we applied each of these donors in tandem with the phosphodiesterase inhibitor IBMX and measured cGMP levels 


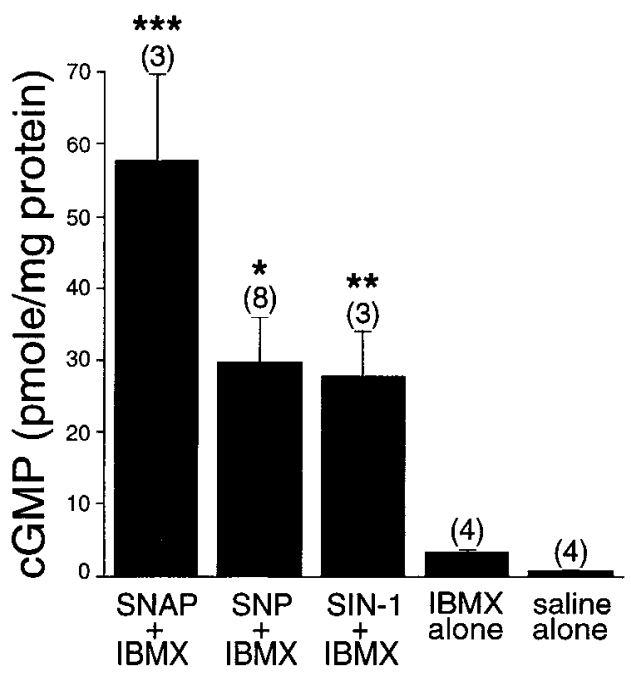

Figure 2. cGMP production in the STNS by NO donors. Each donor, applied with IBMX, elicited a significant increase in cGMP biosynthesis compared with treatment with IBMX alone. Data are the mean \pm SEM, and replicates are shown in parentheses. ${ }^{*} p<0.05 ;{ }^{* *} p<0.01$; ${ }^{* * *} p<$ 0.005 (Student's $t$ test).

with an RIA (Fig. 2). Whereas IBMX alone produced a slight increase in cGMP content compared with basal levels, NO donors produced an additional 10-fold (SNP and SIN-1) to 20-fold (SNAP) increase in CGMP; this indicates that some population of cells in the STNS expresses a guanylate cyclase that can be activated by NO.

\section{Peptides extracted from sinus glands stimulate cGMP metabolism}

The eyestalk sinus gland of decapod crustaceans has long been recognized as a major neurohemal organ and a release site for members of the crustacean CHHs that have cGMP-stimulating effects on a range of peripheral tissues (Sedlmeier and Keller, 1981; Goy et al., 1987, 1990; Keller, 1992). Two closely related forms of $\mathrm{CHH}$ have been identified (CHH-A and $\mathrm{CHH}-\mathrm{B}$; 'Tensen et al., 1991), and these appear to be the only two sinus gland peptides capable of influencing cGMP metabolism (M. Goy, unpublished data). Although $\mathrm{CHHs}$ have been purified from some decapods, including the shore crab Carcinus maenas (Kegel et al., 1989), the crayfish Orconectes (Kegel et al., 1991; Huberman et al., 1993), and the lobster Homarus americanus (Chang et al., 1990; Pavloff and Goy, 1990; Tensen et al., 1991), they have not been purified from the crab used in the present study. The actions of $\mathrm{CHHs}$ are highly species-specific, arising from differences in amino acid sequence (Keller, 1992). For example, C. maenas $\mathrm{CHH}$ does not effect cGMP levels in $H$. americanus muscle when tested at concentrations sufficient to cause a saturating response in crab muscle (Goy et al., 1987). Therefore, we used extracts from $C$. productus sinus glands, a rich source of CHHs (Dircksen et al., 1988). Sinus gland extract was a potent activator of cGMP in the STNS, stimulating a 30-fold increase in cGMP levels compared with treatment with IBMX alone (Fig. 3).

\section{The STNS contains both a membrane and a cytosolic guanylate cyclase}

The fact that NO and the sinus gland extract both stimulate cGMP production in the STNS suggests that independent signaling pathways may be involved. NO is known to activate a soluble guanylate cyclase (Schmidt et al., 1993), whereas sinus gland peptides in the

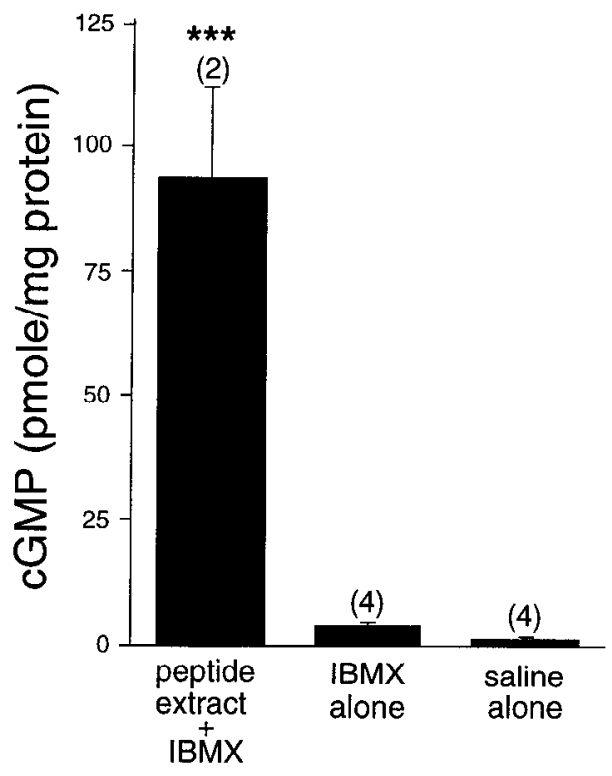

Figure 3. cGMP production in the STNS by extract from the sinus gland. The extract stimulated a significant increase $(p<0.005$, Student's $t$ test $)$ in cGMP production compared with treatment with IBMX alone. Data are the mean $\pm \mathrm{SEM}$, and replicates are shown in parentheses.

CHH family target a membrane cyclase (Goy, 1990) in a manner that appears comparable with the actions of atrial natriuretic peptide on its receptor in vertebrates (Chinkers et al., 1989). To explore whether these two cGMP-production pathways are expressed in the STNS, we first investigated whether this tissue contains both a soluble and a membrane-associated enzyme (Fig. 4). When membranes and cytosol were separated by high-speed centrifugation, both fractions exhibited comparable specific activities of basal guanylate cyclase activity. We tested the relative proportions of cyclase activity across the range of temperatures experienced by these animals in their natural environment (4$20^{\circ} \mathrm{C}$ ). Although both cytosolic and membrane-associated cyclases show marked temperature dependence, the ratio and absolute value of the two forms remain constant at all temperatures (Fig. $4 A$ ). Interestingly, in exoskeletal muscle (the only other crustacean tissue previously tested) the specific activity of the cytosolic cyclase is much lower than that of the membrane cyclase (Goy, 1990), suggesting that the cytosolic enzyme may play a more important role in the STNS than it does in contractile tissues.

When we tested the effect of peptide extract on cyclase activity, we found that, as expected, it nearly doubled the rate of cGMP synthesis by the membrane cyclase (Fig. 4B, open symbols) without any significant effect on the rate of synthesis by the cytoplasmic enzyme (Fig. 4C, open symhols). Also as expected, SNP stimulated the activity of the cytoplasmic cyclase more than threefold (Fig. $4 C$, solid symbols) with no effect on the membrane-associated enzyme (Fig. $4 B$, solid symbols). Somewhat surprisingly, however, SNP only effectively stimulated the cytosolic enzyme at $4^{\circ} \mathrm{C}$. We do not know the reason for the lack of responsiveness of the enzyme at higher temperatures, but we suspect that one explanation is its unusual lability: storage of the cytosolic preparation for even a short period of time caused a complete loss of NO responsiveness at any temperature (data not shown).

\section{Cellular sites of cGMP synthesis in the STNS}

We used whole-mount anti-cGMP ICC to identify individual cGMP-synthesizing cells in the STNS. When NO donors were 

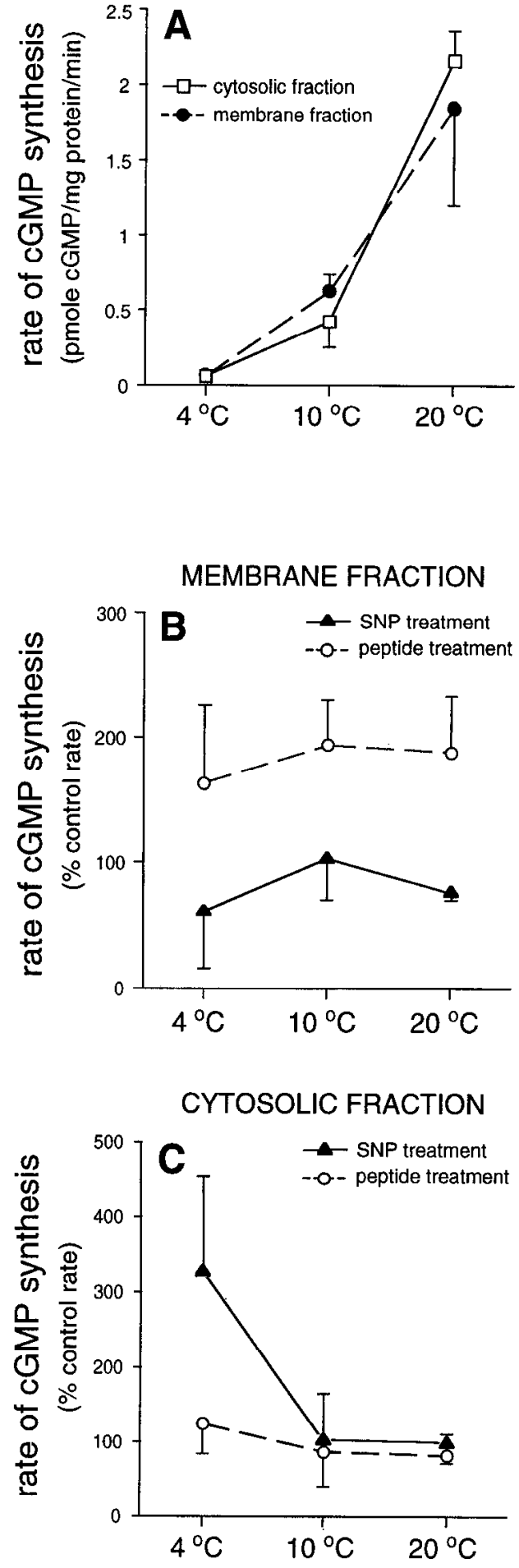

Figure 4. Guanylate cyclase activities in the STNS. A, Basal cyclase activity in cytosolic and membrane fractions of the STNS as a function of temperature. Rates were determined as described in Materials and Methods. $B, C$, Effects of $\mathrm{NO}$ and sinus gland extract on purified membrane and cytosolic fractions, respectively. Each value in $B$ and $C$ gives the stimulated rate compared with the appropriate control (basal) rate. Data are the mean \pm SEM for two to four experiments.

tested in combination with IBMX, each increased cGMP immunoreactivity in specific cells and processes in the STNS (Figs. $5 A-C, 6)$. The effect was the same regardless of NO donor. In the $C G$ and $O G$ (see Fig. 1 for anatomical definitions), the same subset of neurons labeled consistently. In the STG, where soma position is not a reliable indicator of cell identity, labeling was consistent in terms of the total number of responsive cells and their projections.

Staining was absent in untreated nervous systems and in tissues that had been treated with IBMX alone (Fig. 5D,F). Treatment with $10 \mathrm{~mm}$ SNP alone also did not produce intense cGMP immunoreactivity, although in some instances cell bodies stained faintly in the STG (Fig. 5E). This is consistent with RIA studies that demonstrate that whereas IBMX has a relatively small effect on cGMP levels, it is greatly potentiated with the addition of NO (Fig. 2). The small effect of IBMX observed in the RIA studies is apparently below the detection threshold of the antibody used in our immunocytochemical procedures. The IBMX-dependent potentiation observed in both RIA and immunocytochemical studies implies that phosphodiesterase activity is high in these tissues and suggests that cGMP metabolism may be strictly regulated.

Preabsorbing the anti-cGMP primary antiserum with $10^{-5} \mu \mathrm{M}$ cGMP eliminated cGMP immunoreactivity, whereas preabsorbing with $10^{-5} \mu \mathrm{M} \mathrm{CAMP}$ and $10^{-5} \mu \mathrm{M}$ GMP had no effect (data not shown). This is consistent with the specificity observed in previous reports (De Vente et al., 1987; Ewer et al., 1994). No cGMP immunoreactivity was detected when the primary antibody was omitted.

In every cell observed in this study, intracellular cGMP immunoreactivity was distributed diffusely throughout the cytoplasm, with cell somata and axonal projections labeling equally. Transection of all attached nerves before exposure to NO, causing isolation of individual ganglia, had no effect on staining. Further, axons in nerves that had been isolated by transection continued to respond to NO, suggesting that NO is acting on targets located throughout the entirety of the cell, either in the cytoplasm or associated with the membrane.

Among STNS ganglia, the STG contained the greatest proportion of NO-sensitive neurons, with nearly half of all cells (a subpopulation of $\sim 13$ neurons) consistently responding to each NO donor (Fig. 5A-C). The somata of immunopositive neurons were intermixed with somata of nonresponding cells. Staining intensity varied among the responding cells, presumably reflecting a greater production of cGMP in some cells compared with their neighbors. Varied staining intensity is probably not a result of differential antibody penetration for the following reasons: (1) cells of equivalent thickness and depth in the ganglion ranged in staining intensity, and (2) labeling was often most intense in the core of the neuropil. In many cases, labeled processes could be followed from their point of exit in the neuropil to foregut muscle targets. Because soma position is not a reliable indicator of cell identity in the STG, individual motor neurons were tentatively identified by tracing axons to their peripheral targets. For example, Figure $6 E$ shows the $a v n$, which consistently contained four labeled axons; these most likely originate from four GM cells in the gastric CPG circuit.

A single neuron showed cGMP immunoreactivity in the OG after NO treatment (Fig. 6B), although this cell often labeled weakly. This cell extended axons into both inferior oesophageal nerves (ions). Several neurons in the CGs labeled consistently (Fig. 6A). The most prominent was a large neuron with an elongate soma (60-70 $\mu \mathrm{m}$ wide, $100-150 \mu \mathrm{m}$ long) positioned at the apex of the CG. This cell sent a large axon toward the suboesophageal ganglion via the circumoesophageal connectives, and is probably the homolog of the giant neuron that is immunoreactive for proctolin and dopamine in lobster (Siwicki et al., 
Figure 5. NO-responsive neurons in the STG. Patterns of cGMP immunoreactivity obtained after treatments with (A) $1 \mathrm{~mm}$ SNAP and $0.5 \mathrm{~mm} \mathrm{IBMX,(B)} 10 \mathrm{~mm}$ SNP and 0.5 mM IBMX, $(C) 1$ mM SIN-1 and 0.5 mM IBMX, $(D) 0.5$ mM IBMX alone, $(E) 10 \mathrm{~mm}$ SNP alone, or $(F)$ untreated. Note that soma position is variable, and thus is not a reliable indicator of cell identity in $A-C$.
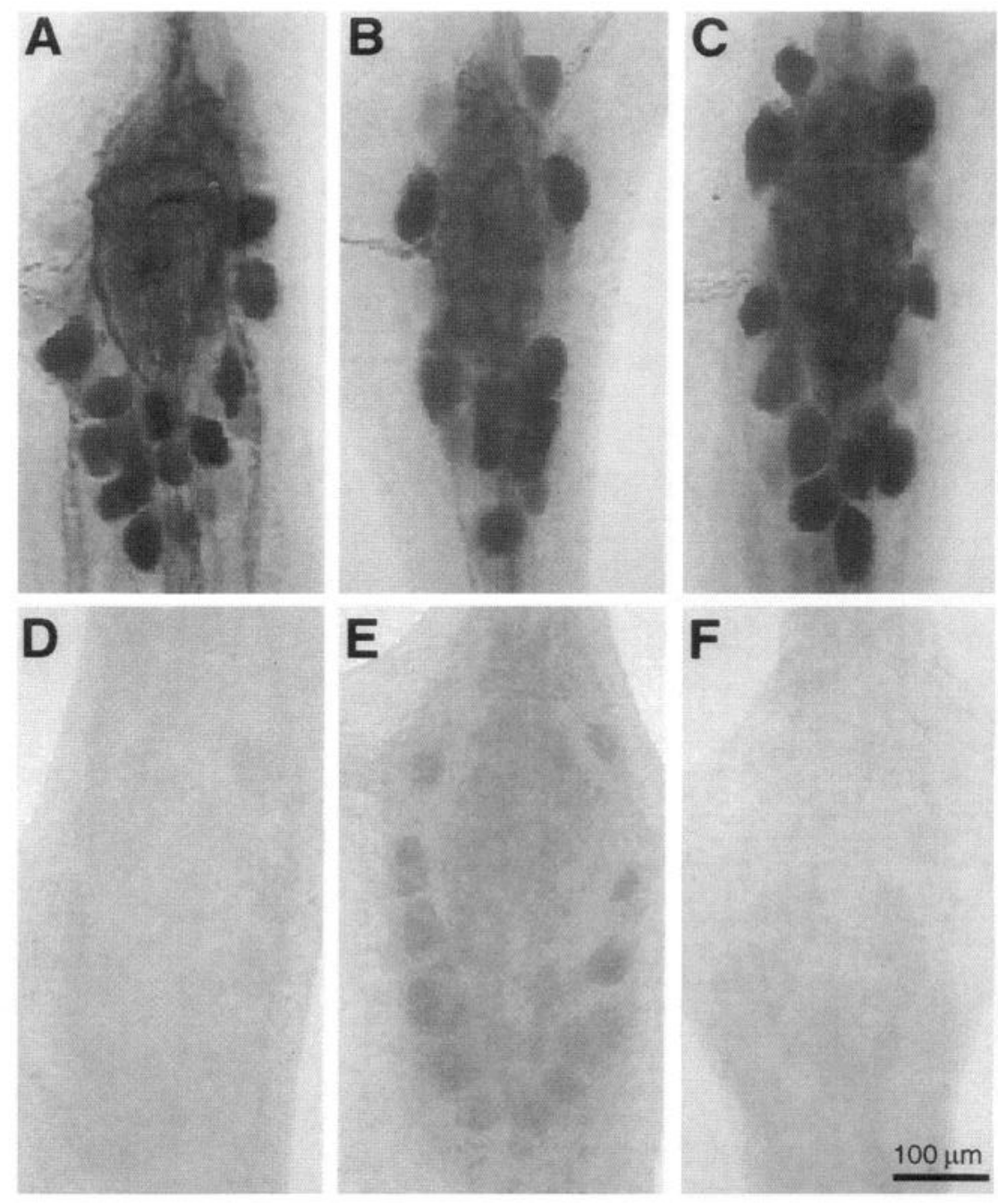

1987). Two or three additional large cells in the CG, as well as a cluster (5-8) of intermediate-sized neurons and many smaller cells, were consistently immunopositive for cGMP after NO treatment.

Among anterior nerves the sons (Fig. 6D), ions (Fig. 6B), avns (Fig. 6E), and $\operatorname{stn}$ (Fig. 6C) contained labeled axons; no staining was observed in the ivn. In posterior nerves, cGMP immunoreactivity was usually confined to the $d v n, d g n, d l v n, v l v n$, and $p d n$. No staining was observed in the $m v n$. Finally, NO donors activated cGMP synthesis in the gastropyloric receptor cells (Fig. 6C), which reside in the vlvn (Katz and Harris-Warrick, 1990).

Surprisingly, we did not observe cGMP-immunopositive cells after treatment with sinus gland extract and IBMX, despite our observation that this treatment produces a 30 -fold increase in cGMP levels as measured by RIA (Fig. 3). We cannot explain this discrepancy, but we suggest that one of the following possibilities may apply. First, subcellular pools of cGMP are differentially susceptible to fixation with paraformaldehyde (de Vente et al., 1987), and it is possible that the membrane and cytosolic guanylate cyclases in the STNS are mobilizing distinct pools of cGMP. Consequently, cGMP produced by a membrane cyclase may be lost via diffusion or elution as the tissue was prepared for wholemount ICC. Second, the antibody used for whole-mount ICC is less sensitive than the antibody used for RIA (e.g., although RIA measurements detected a fourfold increase in cGMP levels with IBMX treatment alone, this was not detected immunocytochem- ically). It is possible that peptide treatments induced a small (subthreshold for immunocytochemical detection) cGMP increase distributed across many STNS cells (e.g., neurons, glia, and sheath cells), whereas NO treatments induced a comparatively large (and thus detectable) cGMP increase in a small subset of neurons.

\section{Tissue distribution of NO- and peptide-activated cGMP}

Previous studies have indicated that the actions of $\mathrm{CHH}$ and related peptides are broad-based, elevating cGMP levels in many types of tissues. In lobster, CHHs stimulate cGMP synthesis in leg muscle, hepatopancreas, heart, testis, supraoesophageal ganglion, and ventral nerve cord, among others (Goy et al., 1987). In contrast, the distribution of an NO-sensitive cyclase is more restricted. For example, although lobster muscle contains a soluble cyclase, this enzyme does not respond to NO (Goy, 1990).

We evaluated the stimulatory effects of $\mathrm{NO}$ and sinus gland extract (tested in the presence of IBMX and compared with control tissues treated with IBMX alone) on muscle, hepatopancreas, STNS, and brain (Fig. 7). Only the STNS exhibited an increase in cGMP content in response to NO (Fig. 7B). Interestingly, applying IBMX alone caused a fivefold increase in cGMP levels in the brain, but had no effect on other, non-neuronal tissues (data not shown). An NO-signaling pathway has been identified in the crustacean brain (Johansson and Carlberg, 1994). It is possible that IBMX applications potentiated the effects of 

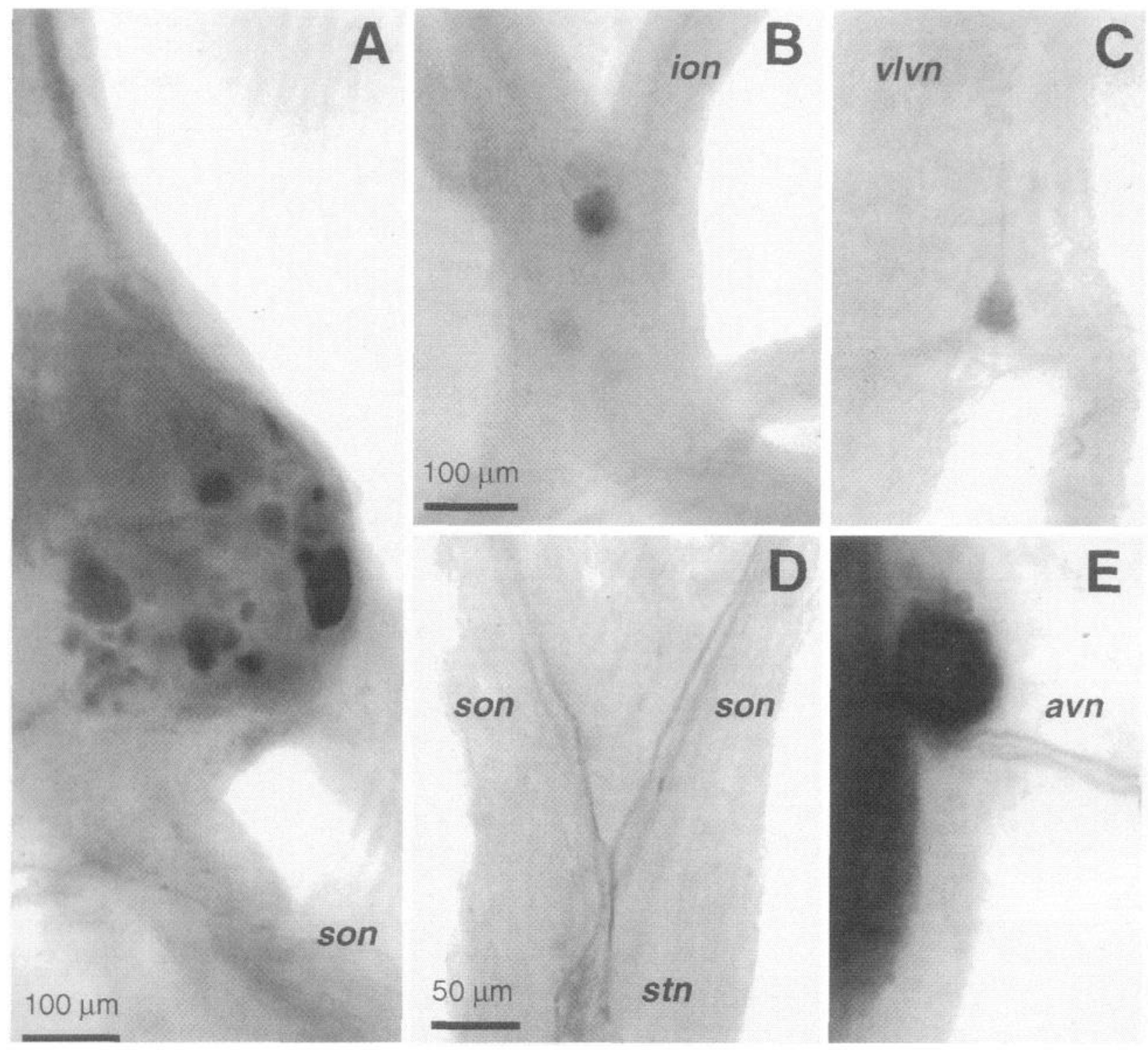

Figure 6. NO-responsive neurons elsewhere in the STNS. $A$, Cell somata in the commissural ganglion. $B$, A single neuron in the oesophageal ganglion. $C$, The gastropyloric receptor cell in the vlvn. D, Axonal projections in the stn and sons. E, Four cGMP-immunopositive axons exiting the central neuropil of the STG. See Figure 1 for anatomical definitions.

endogenously generated NO and that the level of endogenous NO is sufficient to saturate the system.

As expected, the sinus gland extract was a potent activator of cGMP in all tissues surveyed (Fig. 7A). This probably reflects the broad control over cGMP metabolism by members of the hyperglycemic family of peptides (Sedlmeier and Keller, 1981; Goy, 1987). However, the sinus gland contains many other neuropeptides, and we cannot rule out possible effects of non- $\mathrm{CHH}$ peptides on cGMP production. Taken together, these results illustrate a sharp contrast between the global regulation of cGMP biosynthesis by peptides originating from the sinus gland, and the selective stimulation of cGMP in the nervous system by NO.

\section{DISCUSSION}

As a model system, the crustacean STNS has revealed a rich variety of ways by which synaptically delivered neurotransmitters can modulate the rhythmic motor output generated by dynamic circuits. Participatory roles for cyclic nucleotides in this process, however, are poorly understood. In this paper, we demonstrate two pathways for activating cGMP metabolism in the STNS that are mediated by distinct guanylate cyclases. Our findings raise the possibility that peptides in the $\mathrm{CHH}$ family or enzymes that generate NO may play a role in shaping motor output from the STNS. The observations presented above also provide a framework in which to study guanylate cyclase activation and the subsequent effects of cGMP on rhythmic motor output from CPGs.

In this context, it is of obvious importance to consider possible biological sources and routes of delivery of $\mathrm{CHH}$ and $\mathrm{NO}$ to the STNS. The primary site of synthesis and release of $\mathrm{CHH}$ is the sinus gland (Dircksen et al., 1988; Keller et al., 1994), although small amounts have also been detected in pericardial organs (Keller et al., 1985). The sinus gland and the pericardial organs 

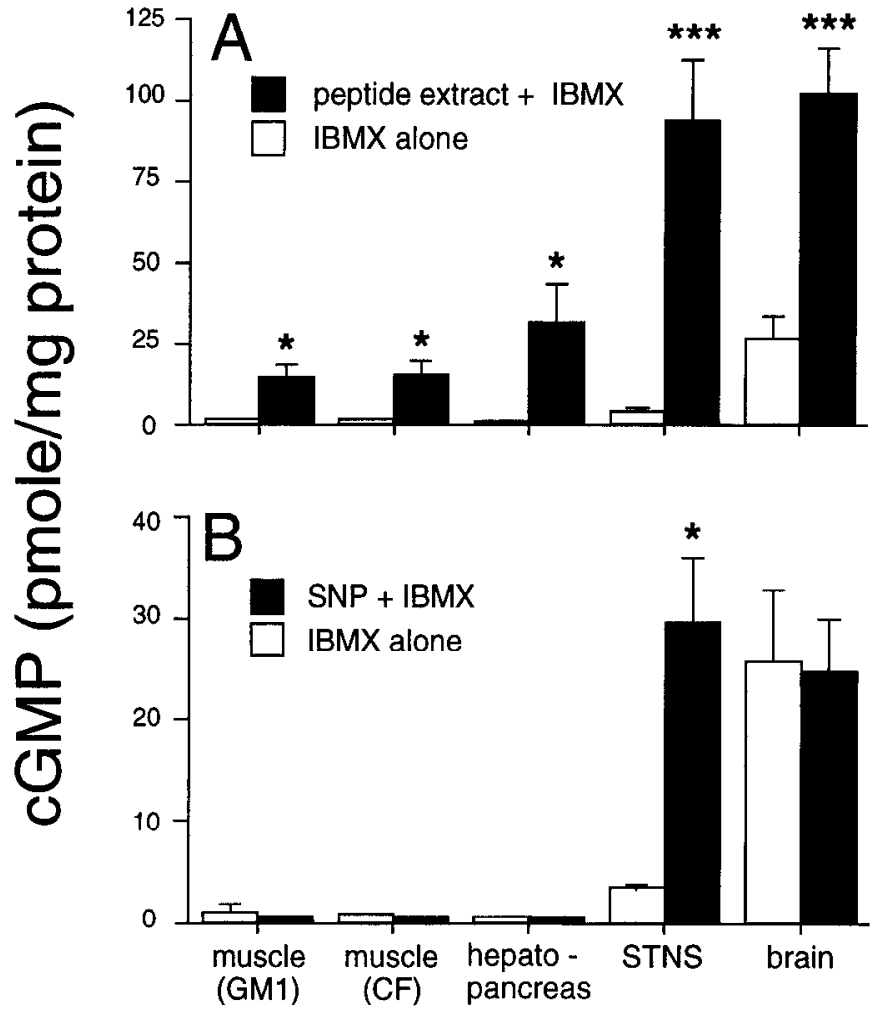

Figure 7. Comparison of tissue responses to NO $(A)$ and sinus gland extract $(B)$. The effect of each agent in the presence of IBMX is compared with treatment with IBMX alone. $* p<0.05 ; * * * p<0.005$ (Student's $t$ test). $G M I$ is a foregut muscle, and $C F$ refers to muscles of the cor frontale in the ophthalmic artery. Data are the mean \pm SEM for four or more experiments, with the exception of experiments testing peptide extract effects on muscle and nervous tissue, which were performed in duplicate.

are both well characterized neurohemal organs that release bioactive peptides and amines into the circulation. Released materials spread rapidly throughout the animal and can affect the physiological properties of targets as diverse as postural muscles (Livingstone et al., 1980), heart (Worden et al., 1995), and hepatopancreas (Keller et al., 1985). It is feasible, therefore, that blood-borne CHH could regulate cGMP metabolism in the STNS. Interestingly, $\mathrm{CHH}$ differs from other sinus gland peptides in that it is lacking within the CNS and the STNS. For example, proctolin, red pigment concentrating hormone-like, and allatostatin-like peptides have been immunocytochemically mapped to the crab sinus gland (Christie et al., 1995); neurons immunopositive for these peptides also project directly to the STG, where they serve modulatory functions in STG circuits (Marder et al., 1986; Nusbaum and Marder, 1988; Skiebe and Schneider, 1994). Consequently, if members of the $\mathrm{CHH}$ peptide family are the active cGMP-stimulating component of the sinus gland extract, it is likcly that they scrve a gencral function in regulating cellular homeostasis that is common to many tissues rather than unique to the STNS (e.g., glycogen metabolism).

With regard to an endogenous source of NO, the situation is less clear. NOS generates NO. It is widely accepted that nicotinamideadenine-dinucleotide phosphate (NADPH)-diaphorase histochemistry (paraformaldehyde fixation) (Vincent and Kimura, 1992) is diagnostic for the presence of neuronal NOS. When we applied this technique to the STNS and foregut musculature, we found no label- ing (data not shown). Perhaps NO originates from some other, non-neuronal tissue in the vicinity of the STNS. For example, diaphorase staining or NOS activity in non-neuronal tissues has been reported in other arthropods (Radomski et al., 1991; Dow et al., 1994; Müller and Bicker, 1994). Interestingly, Radomski et al. (1991) have shown that Limulus hemocytes contain an NOS, suggesting that $\mathrm{NO}$ is generated in the arthropod hemolymph. In decapod crustaceans, the STG is positioned within the lumen of the ophthalmic artery, raising the possibility that STG neurons respond in vivo to NO generated in the blood. Alternatively, the absence of NADPHdiaphorase labeling in the STNS may reflect an unusual sensitivity of the crustacean enzyme to paraformaldehyde fixation, as has been shown for the endothelial form of vertebrate NOS (Dinerman et al., 1994). Finally, we must consider the possibility that the NO-sensitive guanylate cyclase that we have identified in the crab STNS is actually activated in vivo by ligands other than NO (see Morton and Giunta, 1992).

Unlike the $\mathrm{CHH}$ peptides, which so far have been identified only in crustaceans (Keller, 1992) and perhaps in insects (Audsley et al., 1992), NO has been implicated in a wide variety of physiological functions across a diverse array of species. In vertebrates, $\mathrm{NO}$ is active in both neural and non-neural tissues, where it plays key roles in vascular, digestive, neuronal, and immune functions (Garthwaite and Boulton, 1995; Konturek and Konturek, 1995; Umans and Levi, 1995). Accumulating evidence also supports a role for $\mathrm{NO}$ as a physiological regulator in invertebrate species. Among insects, NO-signaling pathways have been characterized in the CNS of the locust (Elphick et al., 1993, 1995; Müller and Bicker, 1994), in the salivary gland of the bloodsucking bug Rhodnius prolixus (Ribeiro and Nussenzveig, 1993; Ribeiro et al., 1993), and in the Malpighian tubules of Drosophila (Dow et al., 1994). In molluscs, NOS-immunopositive neurons have been identified in the buccal ganglia of Lymnaea, and NO stimulates motor output from buccal CPGs (Moroz et al., 1993, 1994). In crustaceans, Johansson and Carlberg (1994) have biochemically demonstrated NOS activity and used NADPH-diaphorase histochemistry to map the distribution of a NOS-like enzyme in the crayfish deutocerebrum, an observation recently confirmed by Talavera et al. (1995). Interestingly, NOS activity is prominently localized to olfactory centers in vertebrates (Breer and Shepherd, 1993), arthropods (Johansson and Carlberg, 1994; Müller and Bicker, 1994; Elphick et al., 1995), and molluscs (Gelperin, 1994), suggesting that certain functions of NO in the nervous system may be preserved across phyla (cf. Elphick et al., 1995). Taken together, these studies suggest that signaling pathways utilizing NO as an intercellular messenger have been evolutionarily conserved. Our data support this and suggest a possible role for NO as a neuronal messenger in the crustacean STNS.

NO has been shown to control rhythmic activity in other neuronal networks. For example, NO increases the frequency of oscillation in Limax procerebral neurons (Gelperin, 1994) and dampcns oscillations in nctworks of mammalian thalamocortical neurons (Pape and Mager, 1992). The diversity of substrates for cGMP, as well as the complex and dynamic aspects of STG circuitry, makes it difficult to predict an outcome of NO-activated cGMP synthesis in the STG. Additional work examining the effects of NO on both individual identified neurons, and on the production of patterned motor output from oscillating networks of cells, is required. In this regard, it is intriguing that only a subpopulation of neurons in the STG is sensitive to NO. Whether 
cGMP is having a similar physiological effect in all NO-responsive cells is an important question that needs to be addressed.

In summary, we have demonstrated that the crustacean STNS contains at least two distinct signaling pathways that stimulate cGMP metabolism. One pathway, activated by NO, is apparently restricted to the nervous system, whereas the other pathway, activated by sinus gland components (probably members of the $\mathrm{CHH}$ peptide family), is broadly distributed in many tissues. This work provides a starting point for physiological analyses of cGMP at the following levels of complexity: (1) in single, identifiable neurons within the gastric and pyloric networks in the $S \mathrm{SI}$, and (2) at the circuit level, where the effects of cGMP on patterned motor production can now be explored. In addition, the expcrimentally accessible STNS offers a unique opportunity to compare the physiological roles of the cytoplasmic isoform of guanylate cyclase (which can be activated by NO in a prominent subset of neurons) with the membrane isoform (which can be activated by $\mathrm{CHH}$ in an as yet unknown, but probably distinct, population of cells).

\section{REFERENCES}

Audsley N, McIntosh C, Phillips JE (1992) Isolation of a neuropeptide from locust corpus cardiacum which influences ileal transport. J Exp Biol 173:261-274.

Baccari MC, Calamai F, Staderini G (1994) Modulation of cholinergic transmission by nitric oxide, VIP and ATP in the gastric muscle. NeuroReport 5:905-908.

Bradford MM (1976) A rapid and sensitive method for the quantitation of microgram quantities of protein utilizing the principle of protein-dye binding. Anal Biochem 72:248-254.

Breer H, Shepherd GM (1993) Implications of the NO/cGMP system for olfaction. Trends Neurosci 16:5-9.

Brooker G, Harper JF, Terasaki WL, Moylan RD (1979) Radioimmunoassay of cyclic AMP and cyclic GMP. Adv Cycl Nucl Res 10:1-33.

Chang ES, Prestwich GD, Bruce MJ (1990) Amino acid sequence of a peptide with both molt-inhibiting and hyperglycemic activities in the lobster, Homarus americanus. Biochem Biophys Res Commun 171:818-826.

Chinkers M, Garbers DL, Chang MS, Lowe DG, Chin H, Goeddel DV, Schulz $S$ (1989) $\Lambda$ membrane form of guanylate cyclase is an atrial natriuretic peptide receptor. Nature 338:78-83.

Christie AE, Skiebe P, Marder E (1995) Matrix of neuromodulators in neurosecretory structures of the crab Cancer borealis. J Exp Biol 198:2431-2439.

De Vente J, Steinbusch HWM, Schipper J (1987) A new approach to immunocytochemistry of $3^{\prime}, 5^{\prime}$-cyclic guanosine monophosphate: preparation, specificity, and initial application of a new antiserum against formaldehyde-fixed $3^{\prime}, 5^{\prime}$-cyclic guanosine monophosphate. Neuroscience 22:361-373.

Dinerman JL, Dawson TM, Schell MJ, Snowman A, Snyder SH (1994) Fndothelial nitric oxide synthase localized to hippocampus pyramidal cells: implications for synaptic plasticity. Proc Natl Acad Sci USA 91:4214-4218.

Dircksen H, Webster SG, Keller R (1988) Immunocytochemical demon stration of the neurosecretory systems containing putative moultinhibiting hormone and hyperglycemic hormone in the eyestalk of brachyuran crustaceans. Cell Tissue Res 251:3-12.

Dow JAT, Maddrell SHP, Davies S, Skaer NJV, Kaiser K (1994) A novel role for the nitric oxide-cGMP signaling pathway: the control of epithelial function in Drosophila. Am J Physiol 266:R1716-R1719.

Elphick MR, Green IC, O'Shea M (1993) Nitric oxide synthesis and action in an invertebrate brain. Brain Res 619:344-346.

Elphick MR, Rayne RC, Riveros-Morena V, Moncada S, O'Shea M (1995) Nitric oxide synthesis in locust olfactory interneurones. J Exp Biol 198:821-829.

Ewer J, De Vente J, Truman JW (1994) Neuropeptide induction of cyclic GMP increases in the insect CNS: resolution at the level of single identifiable neurons. J Neurosci 14:7704 7712.

Gelperin A (1994) Nitric oxide mediates network oscillations of olfactory interneurons in a terrestrial mollusc. Nature 369:61-63.

Goy MF (1990) Activation of a membrane guanylate cyclase by an invertebrate peptide hormone. J Biol Chem 265:20220-20227.
Goy MF (1991) cGMP: the wayward child of the cyclic nucleotide family. Trends Neurosci 14:293-299.

Goy MF, Mandelbrot DA, York CA (1987) Identification and characterization of a polypeptide from a lobster neurosecretory gland that induces cGMP accumulation in lobster neuromuscular preparations. J Neurochem 48:954-966.

Harris-Warrick RM, Marder E, Selverston AI, Moulins M, editors (1992) Dynamic biological networks: the stomatogastric nervous system. Boston: MIT.

Huberman A, Aguilar MB, Brew K, Shabanowitz J (1993) Primary structure of the major isomorph of the crustacean hyperglycemic hormone (CHH-I) from the sinus gland of the Mexican crayfish Procambarus bouvieri: interspecies comparison. Peptides 14:7-16.

Hunter AB, Greenwood AB (1962) Preparation of iodine-131 labelled human growth hormone of high specific activity. Nature 194:495.

Johansson KUI, Carlberg M (1994) NADPH-diaphorase histochemistry and nitric oxide synthase activity in deutocerebrum of the crayfish, Pacifastacus leniusculus (crustacea, decapoda). Brain Res 649:36-42.

Katz PS, Harris-Warrick RM (1990) Neuromodulation of the crab pyloric central pattern generator by serotonergic/cholinergic proprioceptive afferents. J Neurosci 10:1495-1512.

Kegel G, Reichwein B, Weese S, Gaus G, Peter-Katalinic J, Keller R (1989) Amino acid sequence of the crustacean hyperglycemic hormone (CHH) from the shore crab, Carcinus maenas. FEBS Lett 255:10-14.

Kegel G, Reichwein B, Tensen CP, Keller R (1991) Amino acid sequence of crustaccan hyperglycemic hormonc $(\mathrm{CHH})$ from the crayfish, Orconectes limosus: emergence of a novel peptide family. Peptides 12:909-913.

Keller K (1992) Crustacean neuropeptides: structures, functions and comparative aspects. Experientia 48:439-448.

Keller R, Jaros PP, Kegel G (1985) Crustacean hyperglycemic neuropeptides. Amer Zool 25:207-221.

Konturek SK, Konturek PC (1995) Role of nitric oxide in the digestive system. Digestion 56:1-13.

Livingstone MS, Harris-Warrick RM, Kravitz EA (1980) Serotonin and octopamine produce opposite postures in lobsters. Science 208:76-79.

Marder E, Hooper SL, Siwicki KK (1986) Modulatory action and distribution of the neuropeptide proctolin in the crustacean stomatogastric nervous system. J Comp Neurol 243:454-467.

Moroz LL, Park JH, Winlow W (1993) Nitric oxide activates buccal motor patterns in Lymnaea stagnalis. NeuroReport 4:643-646.

Moroz LL, Winlow W, Turner RW, Bulloch AG, Lukowiak K, Syed NI (1994) Nitric oxide synthase-immunoreactive cells in the CNS and periphery of Lymnaea. NeuroReport 5:1277-1280.

Morton DB, Giunta MA (1992) Eclosion hormone stimulates cyclic GMP levels in Manduca sexta nervous tissue via arachidonic acid metabolism with little or no contribution of nitric oxide. J Neurochem 59:1522-1530.

Müller U, Bicker G (1994) Calcium-activated release of nitric oxide and cellular distribution of nitric oxide-synthesizing neurons in the nervous system of the locust. J Neurosci 14:7521-7528.

Mulloney B, Selverston AI (1974) Organization of the stomatogastric ganglion in the spiny lobstcr. I. Neurons driving the latcral tecth. J Comp Physiol [A] 91:1-32.

Nusbaum MP, Marder E (1988) A neuronal role for a crustacean red pigment concentrating hormone-like peptide: neuromodulation of the pyloric rhythm in the crab, Cancer borealis. J Exp Biol 135:165-181.

Pape H, Mager R (1992) Nitric oxide controls oscillatory activity in thalamocortical neurons. Neuron 9:441-448.

Pavloff MS, Goy MF (1990) Purification and chemical characterization of peptide G1, an invertebrate neuropeptide that stimulates cyclic GMP metabolism. J Neurochem 55:788-797.

Radomski MW, Martin JF, Moncada S (1991) Synthesis of nitric oxide by the haemocytes of the American horseshoe crab (Limulus polyphemus). Phil Trans R Soc Lond [Biol] 334:129-133.

Ribeiro JMC, Nussenzveig RH (1993) Nitric oxide synthase activity from a hematophagous insect salivary gland. FEBS Lett 330:165-168.

Ribeiro JMC, Hazzard J, Nussenzveig RH, Champagne DE, Walker FA (1993) Reversible binding of nitric oxide by a salivary heme protein from a bloodsucking insect. Science 260:539-541.

Rodríguez-Membrilla A, Martínez V, Jiménez M, Goñalons E, Vergara P (1995) Is nitric oxide the final mediator regulating the migrating myoelectric complex cycle? Am J Physiol 268:G207-G214. 
Schmidt HHHW, Lohmann SM, Walter U (1993) The nitric oxide and cGMP signal transduction system: regulation and mechanism of action. Biochim Biophys Acta 1178:153-175.

Sedlmeier D (1988) The crustacean hyperglycemic hormone (CHH) releases amylase from the crayfish midgut gland. Regul Pept 20:91-98.

Sedlmeier D, Keller R (1981) The mode of action of the crustacean neurosecretory hyperglycemic hormone. I. Involvement of cyclic nucleotides. Gen Comp Endocrinol 45:82-90.

Siwicki KK, Beltz BS, Kravitz EA (1987) Serotonergic, dopaminergic, and cholinergic neurons in the lobster, Homarus americanus. J Neurosci $7: 522-532$.

Skiebe P, Schneider H (1994) Allatostatin peptides in the crab stomatogastric nervous system: inhibition of the pyloric motor pattern and distribution of allatostatin-like immunoreactivity. J Exp Biol 194:195-208.

Southam E, Garthwaite J (1991) Comparative effects of some nitric oxide donors on cyclic GMP levels in rat cerebellar slices. Neurosci Lett 130:107-111.

Stryer L (1986) Cyclic GMP cascade of vision. Annu Rev Neurosci 9:87-119.

Talavera E, Martínez-Lorenzana G, León-Olea M, Sánchez-Alvarez M, Sánchez-Islas E, Pellicer F (1995) Histochemical distribution of NADPH-diaphorase in the cerebral ganglion of the crayfish Cambarellus montezumae. Neurosci Lett 187:177-180.
Tensen CP, De Kleijn DPV, Van Herp F (1991) Cloning and sequence analysis of cDNA encoding two crustacean hyperglycemic hormones from the lobster Homarus americanus. Eur J Biochem 200:103-106.

Umans JG, Levi R (1995) Nitric oxide in the regulation of blood flow and arterial pressure. Annu Rev Physiol 57:771-790.

Vincent SR, Kimura H (1992) Histochemical mapping of nitric oxide synthase in the rat brain. Neuroscience 46:755-784

Watson AHD, Burrows M (1981) Input and output synapses on identified motor neurones of a locust revealed by the intracellular injection of horseradish peroxidase. Cell Tissue Res 215:325-332.

Wiegand RC, Kato J, Huang MD, Fok KF, Kachur JF, Currie MG (1992) Human guanylin: cDNA isolation, structure, and activity. FEBS Lett 311:150-154.

Worden MK, Kravitz EA, Goy MF (1995) Peptide F1, an N-terminally extended analog of FMRFamide, enhances contractile activity in multiple target tissues in lobster. J Exp Biol 198:97-108.

Yuan SY, Bornstein JC, Furness JB (1995) Pharmacological evidence that nitric oxide may be a retrograde messenger in the enteric nervous system. Br J Pharmacol 114:428-432.

Yuen PST, Garbers DL (1992) Guanylyl cyclase-linked receptors. Annu Rev Neurosci 15:193-225. 